The APA also noted that appropriate procedures for consent had not yet been agreed and that further research on the indications, benefits and adverse effects of ECT in young people was required. We do not know if the present findings can be generalised to the whole of the UK, but we found no evidence for the inappropriate use of ECT in young people over the past ten years in Edinburgh.

American Psychiatric Association Task Force on ECT (1990)

The practice of ECT: recommendations for treatment, training and privileging. Convulsive Therapy, 6, 85-120.

Alastair CoOK Allan SCOTT

Royal Edinburgh Hospital

Morningside Terrace

Edinburgh EHIO 5HF

\section{Community care and suicide}

SIR: Boer \& Briscoe (Journal, June 1992, 160, 867) state that their analysis of overall rates of suicide and open verdicts in three West-country health districts has not revealed evidence that a change of emphasis towards community care is associated with demonstrable effects on suicide rates.

The previous inquiry based in one of these health districts (Journal, February 1992, 160, 149-153) indicated that the raw numbers of suicides were too small to allow firm conclusions to be drawn from them. Even though Drs Boer and Briscoe amalgamated three districts in their data analysis, the numbers of suicides and open verdicts must surely have remained small, although they give no details. Such statistical problems, related to the low base rate of suicide, mean that the overall rate of suicides and open verdicts based on small populations inevitably remains an inadequate index of competence of service provision.

A more sensitive measure of the effectiveness of a mental-health service is the rate of suicides and open verdicts in those persons who have made direct contact with its various components. We believe it is important that each discrete service should set up a register which is able to monitor such data in a reliable way, including both community and hospital-style facilities. In this way, trends in suicides and open verdicts can be identified, as well as foci of particular difficulty which may need attention. Such a register can be set up relatively easily without requirement of extra administrative staff: a recent study has demonstrated that information about suicides and open verdicts in Avon, wherever they have died in the UK, was readily available.

Regular clinical multidisciplinary audit of unexpected deaths in persons who have recently been in contact with psychiatric services is therefore feasible. and we believe essential, in evaluating the effectiveness of service provision. This is particularly so at the present time of rapid change in service organisation.

H. G. MoRgaN

University of Bristol

C. A. Vassilas

Department of Mental Health

41 St Michael's Hill

Bristol BS2 8DZ

\section{5-HT, receptors, hallucinations, and dementia}

SIR: I read with interest Haddad \& Benbow's article (Journal, August 1992, 161, 263-265). I would like to comment on the strong association between the dementing processes and isolated visual hallucinations as indicated by the authors.

A number of investigators have hypothesised that hallucinogens act as direct agonists at the 5-hydroxytryptamine ${ }_{2}\left(5-\mathrm{HT}_{2}\right)$ receptor in the central nervous system (for review see Pierce \& Peroutka, 1990). The affinity of hallucinogenic agents for 5- $\mathrm{HT}_{2}$ binding sites correlates significantly with their potencies for causing hallucinations in humans (Glennon et al, 1984) and results in a rapid desensitisation and downregulation of the central 5- $\mathrm{HT}_{2}$ receptors in humans and laboratory animals (Leysen \& Pauwels, 1991).

Downregulation of $5-\mathrm{HT}_{2}$ receptors has also been reported consistently during the dementing processes (Cross et al, 1986; Gross-Iseroff et al, 1990).

The initial rapid desensitization and down regulation of 5-HT $\mathrm{HT}_{2}$ receptors may therefore explain the early presence of hallucinations during the dementing processes.

Cross, A. J., Crow, T. J., Ferrier, I. N., et al (1986) The selectivity of the reduction of serotonin S2 receptors in Alzheimer-type dementia. Neurobiology of Aging, 7, 3-7.

Glennon, R. A., Titeler, M. \& MCKenney, J. D. (1984) Evidence for 5-HT, involvement in the mechanism of action of hallucinogenic agents. Life Sciences, 35, 2505-2511.

Gross-Isseroff, R., SAlama, D., ISRAEL, M. et al (1990) Autoradiographic analysis of age-dependent changes in serotonin S-HT, receptors of the human brain postmortem. Brain Research, 519, 223-227.

LeYsen, J. E. \& PAUWELS, P. J. (1990) 5-HT, receptors, roles and regulation. Annals of the New York Academy of Sciences, 600 , 183-193.

Pierce, A. P. \& PeroutKa, S. J. (1990) Antagonist properties of d-LSD at 5 -hydroxytryptamine, receptors. Neuropsychopharmacology, 3, 503-508.

Serdar M. Dursun

Pharmaceutical Sciences Institute

Aston University

Aston Triangle

Birmingham B4 7ET 